Published in final edited form as:

J Mol Cell Cardiol. 2014 June ; 0: 43-53. doi:10.1016/j.yjmcc.2013.11.008.

\title{
The Role of Ubiquitin Ligases in Cardiac Disease
}

\author{
Monte S. Willis ${ }^{1,2}$, Ariana Bevilacqua ${ }^{2}$, Thomas Pulinilkunnil ${ }^{3}$, Petra Kienesberger $^{3}$, Manasi \\ Tannu $^{4}$, and Cam Patterson 5 \\ ${ }^{1}$ McAllister Heart Institute, University of North Carolina, Chapel Hill, NC USA \\ 2Department of Pathology and Laboratory Medicine, University of North Carolina, Chapel Hill, NC \\ USA \\ ${ }^{3}$ Department of Biochemistry and Molecular Biology, Dalhousie Medicine, Dalhousie, New \\ Brunswick Canada \\ ${ }^{4}$ College of Medicine, University of North Carolina at Chapel Hill, Chapel Hill, NC USA \\ ${ }^{5}$ Departments of Cell and Developmental Biology, Medicine (Cardiology), and Pharmacology, \\ University of North Carolina, Chapel Hill, NC USA
}

\begin{abstract}
Rigorous surveillance of protein quality control is essential for the maintenance of normal cardiac function, while the dysregulation of protein turnover is present in a diverse array of common cardiac diseases. Central to the protein quality control found in all cells is the ubiquitin proteasome system (UPS). The UPS plays a critical role in protein trafficking, cellular signaling, and most prominently, protein degradation. As ubiquitin ligases (E3s) control the specificity of the UPS, their description in the cardiomyocyte has highlighted how ubiquitin ligases are critical to the turnover and function of the sarcomere complex, responsible for the heart's required continuous contraction. In this review, we provide an overview of the UPS, highlighting a comprehensive overview of the cardiac ubiquitin ligases identified to date. We then focus on recent studies of new cardiac ubiquitin ligases outlining their novel roles in protein turnover, cellular signaling, and the regulation of mitochondrial dynamics and receptor turnover in the pathophysiology of cardiac hypertrophy, cardiac atrophy, myocardial infarction, and heart failure.
\end{abstract}

\section{Keywords}

cardiac; ubiquitin ligase; cardiomyopathy; ischemic heart disease; heart failure; E3; proteasome

\footnotetext{
(C) 2013 Elsevier Ltd. All rights reserved.

Address correspondence and inquiries to: Monte S. Willis, MD, PhD, FAHA, McAllister Heart Institute, University of North Carolina at Chapel Hill, 2340B Medical Biomolecular Research Building, 111 Mason Farm Road, Chapel Hill, NC 27599-7525, Phone: (919) 843-1938, Fax: (919) 843-4585, monte_willis@ med.unc.edu.

Disclosures

None.

Publisher's Disclaimer: This is a PDF file of an unedited manuscript that has been accepted for publication. As a service to our customers we are providing this early version of the manuscript. The manuscript will undergo copyediting, typesetting, and review of the resulting proof before it is published in its final citable form. Please note that during the production process errors may be discovered which could affect the content, and all legal disclaimers that apply to the journal pertain.
} 


\section{Introduction}

Rigorous surveillance of protein quality control is essestial for the maintenance of normal cardiac function. Dysregulation of this routine protein turnover has been implicated in common cardiac diseases, including cardiac hypertrophy, cardiac atrophy, ischemic heart disease and heart failure. The ubiquitin proteasome system (UPS) is a fundamental regulator of protein quality control in all cells, including the cardiomyocyte, which participates in protein trafficking, cellular signal transduction, and in prominently, degradation. When components of the UPS function normally, the integrity of proteins that make up the sarcomere, mitochondria and cell membrane is maintained, allowing for normal heart function. Conversely, cardiac dysfunction is prominently associated with alterations in UPS function. As part of the UPS, ubiquitin ligases (E3s) have the key role of directing the addition of ubiquitin to specific target proteins, thereby marking them for degradation, decreasing their activity, and/or changing their physical location within the cell. By maintaining protein quality control and regulating many critical cellular processes, cardiac ubiquitin ligases are critically important to maintaining the heart in health and disease. The role cardiac ubiquitin ligases have in health and disease is rapidly expanding, as new research reveals novel protein targets as well as expanding novel functional roles for each cardiomyocyte-specific ubiquitin ligase. This review provides an overview of the UPS in the heart, focusing on ubiquitin ligase activity in cardiac health and disease.

\section{The components of the UPS and how they interact}

The process of protein quality control involves the turnover of cellular proteins as they become damaged over time. This process occurs in multiple steps, whereby damaged proteins (e.g. recognized as chronically misfolded proteins) are recognized and degraded so that newly synthesized proteins can replace them. This process preserves critical cellular functions throughout the cell. The rate of protein turnover varies widely between cellular components, reflecting their function in the cell. For example, proteins in the nucleus and cytosol may be degraded within minutes; muscle actin and myosin turnover occurs in days to weeks [1]. There are two proteolytic systems responsible for protein degradation, the UPS and autophagy-driven lysosomal degradation, and both of these systems are tightly controlled by complex regulatory mechanisms to ensure that protein degradation occurs selectively and in a timely manner [2-4]. The UPS is a tightly regulated signaling cascade generally involving three classes of enzymes: E1 (ubiquitin-activating enzyme), E2 (ubiquitin-conjugating enzyme), and E3 (ubiquitin ligase). As the names of these enzymes imply, the activated ubiquitin created by E1 is handed off to the E2 to prepare the ubiquitin for conjugation, which then interacts with the E3 (Figure 1). In addition to disposing of proteins as part of the cellular protein quality control process, the UPS is also involved in the regulation of transcription factors, functioning of the immune system, the regulation of lysosomal-mediated protein degradation (autophagy), and as a source of amino acids [5, 6].

\section{The Role of Ubiquitin Ligases in Cardiac Disease}

Ubiquitin ligases enact the final step in the ubiquitination cascade and give specificity to the UPS by interacting with specific substrates and tagging them with ubiquitin. Of the 
hundreds of purported ubiquitin ligases identified in the genome, at least nine have been found in cardiac myocytes and are critical to the pathophysiology of common cardiac disease (summarized in Table 1). These include the muscle ring finger family (MuRF1, 2 and 3), atrogin-1/muscle atrophy F-box (MAFBx), c-terminus of heat shock protein 70interacting protein (CHIP), and the murine double minute 2 (MDM2). Casitas b-lineage lymphoma (c-Cb1), ubiquitin-protein ligase E3A (UBE3A/E6AP), and cellular inhibitor of apoptosis (cIAP) have also been described in the heart and most recently, F-box and leucinerich repeat protein 22 (Fbxl22) has been reported [7]. The number of ubiquitin ligases found in the heart, and the fact that each ubiquitin ligase can target multiple proteins, illustrates the high level of influence the UPS has on cardiac function.

Whereas the UPS plays a critical role in maintaining cellular homeostasis under physiologic conditions, the regulation of protein degradation also occurs during the process of cardiac hypertrophy and cardiac atrophy. In cardiac atrophy, increases in protein degradation occur concomitantly with parallel decrease in protein synthesis [8]. Conversely, protein synthesis increases to a greater degree than protein degradation during cardiac hypertrophy $[9,10]$. Specific ubiquitin ligases have been implicated in the processes of cardiac hypertrophy and atrophy. In mice lacking MuRF1 and atrogin-1, an exaggerated cardiac hypertrophy occurs in response to pressure overload-induced; similarly, MuRF1 -/- mice are resistant to dexamethasone-induced cardiac atrophy [11-14]. These studies have been interpreted to illustrated how MuRF1 and Atrogin-1 inhibit pathologic cardiac hypertrophy [11, 12] and how MuRF1 inhibits cardiac atrophy [13, 14], whereas other ubiquitin ligases, such as MDM2 and CHIP, have demonstrated a protective role against cardiomyocyte apoptosis in ischemia/reperfusion injury by targeting p53 for proteasomal degradation [15-18]. Although our understanding of ubiquitin ligases in cardiac disease is growing (Table 1), many more are yet to be found and our understanding of their mechanisms continues to grow.

\section{Ubiquitin Ligases in Protein Turnover}

Though the sarcomere is often envisioned as a static structure, the proteins that make up this contractile unit undergo constant turnover to maintain homeostatic conditions and adapt to physiologic changes. Initial studies of the protein turnover in the heart showed alterations to both protein synthesis and degradation rates after starvation in rats and rabbits $[8-10,19$, 20]. Prior to 2001, the proteasome itself had been implicated in sarcomeric protein turnover [21], but the discovery of the involvement of muscle-specific ubiquitin ligases Atrogin-1 and MuRF1 [22] opened the door for a greater understanding of this highly regulated pathway (Table 1). Subsequent studies illustrated how these and other ubiquitin ligases facilitate the degradation of older, damaged and misfolded sarcomeric proteins so they can be replaced. While these studies illustrate a limited number of substrates for each E3, there is considerable more complexity to E3s in cardiac disease than is suggested by our current knowledge. However, many of the important details that make cardiac E3s disease / stressor dependent is unclear-one possible reason is that the specific substrate may not exist until the heart is stressed as is likely the case of MuRF1's recognition of phospho-c-Jun in ischemiareperfusion injury (Table 1). 
Additionally, the types of ubiquitination chains added to substrates depends on the specific E2(s) that various E3 partner with. Recent studies have illustrated that MuRF1 and CHIP, for example, form different types of ubiquitin chains depending on the E2 they are partnered with [23]. It is not clear how these studies are relevant in different cell types or in vitro vs. in vivo systems-that is-we don't know which E2(s) are present in cardiomyocytes, how they may be species or disease condition specific, or even the actual interactions they are able to make with E3s if they are present. Based on current literature, however, in certain disease / stressed states cardiac sarcomeric proteins described as targets for E3-mediated degradation in different contexts include critical proteins involved directly in muscle contraction and cellular signaling, including myosin heavy chain, myosin light chain, the troponin complex (troponins I/T/C), tropomyosin and titin - all of which have specific $\mathrm{t}_{1 / 2}$ values between three to eight days [1]. Exciting new studies continue to identify novel cardiac ubiquitin ligases that play a role in regulating sarcomere protein turnover critical to the maintenance of heart, including f-box and leucine-rich repeat protein 22 (Fbx122), c-Cbl, and cMLCK.

The cardiac ubiquitin ligase Fbx122 localizes to the Z-disc and specifically degrades aactinin-2 and filamin C [7]. Increasing Fbx122 expression experimentally in vitro initiates degradation of a-actinin- 2 and filamin $\mathrm{C}$, whereas treatment of rat cardiomyocytes with the proteasome inhibitor MG-132 results in a-actinin-2 accumulation and severe contractile dysfunction [7]. When Fbx122 expression is decreased in zebrafish embryos using morpholino-modified antisense oligonucleotides, normal cardiac function is disturbed [7]. Fbx122's role in maintaining cardiac function through the maintenance of a-actinin-2 and filamin $\mathrm{C}$ is consistent with the role a-actinin-2 and filamin $\mathrm{C}$ have in cardiac contractility and mechanosensing [24]. a-Actinin-2 binds actin and titin, among other Z-disc proteins, to maintain proper sarcomere formation and structure [25, 26]. Mutations in a-actinin-2 result in dilated and hypertrophic cardiomyopathies in humans [24, 27]. Filamin C is critical to sarcomere integrity via interaction with actin, forming crosslinks that allow maintenance of the sarcomere under mechanical stress associated with contractility [28]. Disorganization of proteins at the sarcomere including filamin $\mathrm{C}$ can lead to a host of diseases categorized as myofibrillar myopathies [29,30]. Although the role of Fbxl22 in regulating a-actinin-2 and filamin $\mathrm{C}$ turnover in cardiac diseases has not yet been investigated, its putative role in regulating the turnover of these z-disc-associated proteins critical to sarcomere structure and downstream signaling are likely to be involved in diseases associated with sarcomere remodeling, including cardiac hypertrophy, heart failure, cardiac atrophy, and ischemic heart disease.

The casitas b-lineage lymphoma protein (c-Cbl) has recently been identified as a ubiquitin ligase regulating the turnover of myofibrillar proteins involved in focal adhesion in cardiomyocytes. This was discovered through studies investigating the mechanisms by which cathepsin G, released by neutrophils, induces myocyte detachment and apoptosis by down regulating focal adhesion signaling during inflammatory cardiac injury [31]. Experimentally, increasing c-Cbl in isolated neonatal cardiomyocytes causes enhanced degradation of focal adhesion kinase (FAK), paxillin, and troponin I [31]. Conversely, deletion of c-Cbl in myocytes reduces focal adhesion protein degradation, myofibrillar degradation, and reduced myocyte apoptosis induced by cathepsin G [31]. Proteasome inhibition, but not lysosome or calpain inhibition, markedly attenuates the FAK and 
myofibrillar protein degradation [31]. FAK and paxillin have been implicated in the pathogenesis of cardiac hypertrophy and ischemia-reperfusion injury [32-34]) and play a role in physiologic cardiac development [35] and myocyte chemotaxis [36]. c-Cbl's regulation of troponin I, a key regulator of cardiac contractility, illustrates its importance in regulating cardiac function. The activation of $\mathrm{c}-\mathrm{Cbl}$ by cathepsin $\mathrm{G}$ is mediated by epidermal growth factor receptor (EGFR) transactivation, supporting a model in which neutrophil invasion in cardiac inflammation releases cathepsin $\mathrm{G}$, promoting c-Cbl interaction with FAK, paxillin, and troponin I, resulting in enhanced ubiquitination, myofibril degradation, and down-regulation of anti-apoptotic signaling [31]. Although c-Cbl's role in inflammation has been established in the heart, its role in the inflammation associated with ischemic heart disease and heart failure remains to be investigated.

Recent studies have implicated cardiac ubiquitin ligase(s) in the degradation and turnover of the cardiac myosin light chain kinase (cMLCK), a protein that phosphorylates cardiac myosin light chain 2 (MLC2). To determine the mechanisms involved in the process of cardiac hypertrophy decompensation, cMLCK knockout and cardiac-specific transgenic mice were generated to test the hypothesis that MLC2 phosphorylation is involved [37]. These mice were then challenged with pressure overload hypertrophy. Pressure overload led to severe heart failure in cMLCK knockout mice, but not in the cMLCK transgenic mice where cMLCK protein synthesis exceeded degradation [37]. The reduced cMLCK protein during pressure overload was attenuated by proteasome inhibition, independent of both Atrogin-1 and MuRF1, suggesting a role for cardiomyocyte ubiquitin ligases in accelerating cMLCK protein turnover during the transition from compensated cardiac hypertrophy to heart failure, resulting in reduced MLC2 phosphorylation [37]. The identity of these cardiac ubiquitin ligases remains to be determined and indicates a role for the phosphorylation of the sarcomere apparatus, critical to function during cardiac stress. Although our knowledge of the mechanisms involved in cardiac sarcomere proteins turnover is incomplete (Table 2), it is anticipated that many more ubiquitin ligases will be identified in the future that play a role in the maintenance of sarcomere protein integrity and cardiac function. And as discussed above, the cellular context of these E3s in vivo may be critically important to understand the substrates being affected. The types of E2s ubiquitin ligases interact with, the cardiac context (stress, disease, etc.), and the specific substrates affects in vitro and in vivo is largely unaddressed in the current literature and is important to more broadly understand the UPS in context of cardiac disease.

\section{Ubiquitin ligases in the pathophysiology of myocardial infarction}

In humans, myocardial infarction frequently leads to heart failure and is linked to high mortality rates [38]. Although most patients now survive the immediate event by reperfusion intervention, infarcted myocardial tissue undergoes scarring with concomitant structural and functional remodeling of the heart, which may eventually lead to contractile dysfunction and heart failure [38-40]. Despite major advances in the treatment of myocardial infarction, limiting myocardial cell death following ischemia-reperfusion $(\mathrm{I} / \mathrm{R})$ injury remains a challenging clinical endeavor. The role of the ubiquitin ligases Atrogin-1 and MuRF1 in regulating the severity of myocardial infarction and $\mathrm{I} / \mathrm{R}$ injury in response to coronary artery occlusion has recently been reviewed [41]. Here we present subsequent studies implicating 
the ubiquitin ligases CHIP and parkin in the pathophysiology of I/R injury, demonstrating their potential as therapeutic targets.

\subsection{The ubiquitin ligase parkin mediates mitophagy in cardiac I/R injury}

More than three decades ago, Decker and Widenthal demonstrated that 40 minutes of ischemia and subsequent reperfusion resulted in increased autophagy in Langendorff perfused rabbit hearts $[42,43]$. Autophagy, the catabolic mechanism in which cells degrade dysfunctional components through the lysosomal machinery, has recently been shown to be a critical mechanism by which cardiomyocytes protect themselves in ischemic heart disease models [44]. Autophagic clearance of damaged organelles including mitochondria is beneficial for recovery of the myocardium following I/R, as this eliminates further cardiac damage by dysfunctional mitochondria and fuels the process of mitochondrial biogenesis. The selective removal of impaired mitochondria by autophagy (mitophagy) is critical for sustaining optimal cellular function during ischemia, reperfusion and post-infarction recovery since mitochondria are essential organelles that control energy homeostasis and cell survival [45-47].

Recent studies have identified the ubiquitin ligase parkin as a regulator of mitochondria quality control through its regulation of mitophagy. Senescent and damaged mitochondria undergo selective mitophagic elimination and recent studies have illustrated that this occurs through the post-translational modification of the mitochondrial fusion protein mitofusin-2 (Mfn2) in cardiomyocytes [48]. When damaged, Mfn2 recruits the cytosolic ubiquitin ligase parkin to the mitochondria [48], a process that requires PTEN-induced putative kinase protein 1 (PINK1) to phosphorylate Mfn2, which then promotes its parkin-mediated ubiquitination (Figure 3A) [48]. In the absence of Mfn2 in cardiomyocytes, mitophagy is suppressed and abnormal mitochondria with respiratory dysfunction accumulate. Mfn2 -/Drosphila suffer from a dilated cardiomyopathy, demonstrating the importance of parkin in regulating the Mfn2 protein in mitochondrial protein quality control [48]. Parkin is also purported to play an important role in ischemic preconditioning, which affords cardioprotection during a subsequent infarct [49]. Failure to induce parkin translocation to mitochondria and augment mitophagy blunts the cardioprotective effect of ischemic preconditioning in parkin -/- mice [49]. Taken together, these data support an essential role for parkin-mediated quality control of mitochondria in limiting cardiac injury during myocardial infarction and imparting cardioprotective effects of ischemic preconditioning.

\subsection{The ubiquitin ligase / co-chaperone CHIP regulates NF-kB and MAPK signaling in I/R injury}

In addition to parkin, several lines of studies have proposed that heat shock proteins (hsps) and ubiquitin ligases that interact with HSPs are cardioprotective [50, 51]. Heat shock proteins are chaperones that influence protein turnover and reverse protein-misfolding events, thereby promoting cell survival. For example, expression of the inducible heat shock protein hsp70 is augmented following ischemic injury and increasing hsp70 expression experimentally improves functional recovery of the reperfused myocardium [52-54]. CHIP is a co-chaperone/ubiquitin ligase that contains a tetratricopeptide repeat (TPR) domain at its amino terminus, which interacts with members of the hsp family and reduces chaperone 
activity [55-57]. Both hsp70 and CHIP are present in most tissues of the body, with high expression in the heart $[55,58,59]$. In concert with hspSP70/hsc70, CHIP acts as a ubiquitin ligase to target specific proteins to refold and if unsuccessful, to be degraded in a UPSdependent manner (discussed below in section 6).

The physiological importance of CHIP as a master regulator of cardiac protein quality control machinery was established by a series of recent studies. CHIP promotes myocardin and Foxo1 degradation to attenuate smooth muscle cell differentiation [60, 61]. CHIP also inhibits angiotensin II (Ang II)-induced cardiac fibrosis and inflammation through NF- $\mathrm{BB}$ and MAPK pathway inhibition [62]. Specifically, in mice with increased CHIP expression, cardiac apoptosis and fibrosis are attenuated in response to Ang II [62]. Furthermore, Ang II-induced myocardial inflammation is significantly inhibited when CHIP expression is increased in vivo [62]. Conversely, knockdown of CHIP in neonatal cardiomyocytes increases Ang II-induced apoptosis, as well as the expression of proinflammatory cytokines, a process which is dependent on the NF- $\mathrm{kB}$ and MAPK pathways. CHIP also functions as a physiological regulator of cellular apoptosis due to its ability to inhibit apoptosis signalregulated kinase 1-mediated apoptosis via its degradation [18].

CHIP deficiency causes marked cell death of cardiomyocytes and endothelial cells in response to ischemic injury [16]. Interestingly, increasing CHIP expression protects against myocyte apoptosis during ischemia injury by promoting p53 degradation [63]. A screen of a mouse heart cDNA library identified CHIP as a novel p53 antagonist wherein inverse correlation was shown between CHIP and p53 protein levels, implying the possible involvement of CHIP downregulation in the initiation of p53 accumulation after acute hypoxic stress [63]. Indeed, CHIP protects cardiomyocytes from hypoxia-induced p53mediated apoptosis. Mice lacking CHIP (CHIP-/-) have unaltered cardiac function at baseline [16]. However, in response to exercise, CHIP-/- mice respond with an enhanced autophagic response and exaggerated cardiac hypertrophy without abnormalities in cardiac function, signifying physiologic and not pathologic hypertrophy [64]. However, CHIP-/mice exhibit decreased survival, increased arrhythmias and myocardial injury when challenged with I/R injury [16] (see Figure 2B), with increased arrhythmogenic susceptibility during the reperfusion period and increased mortality independent of gender [16]. Furthermore, CHIP-/- mice are highly susceptible to vascular and cardiomyocyte apoptosis induced by coronary artery ligation and were more prone to sudden death after induction of myocardial infarction [16]. These data allude to the powerful role played by endogenous CHIP as a control point in offering protection against I/R injury. Despite this protective role for CHIP, it still remains unclear how CHIP is activated in vivo. Nor is it clear how CHIP exerts dual control of protein folding and degradation machinery.

Together, these data support the cardioprotective role of ubiquitin ligases against myocardial infarction. Generation of mice with cardiac-specific deletion or overexpression of CHIP or parkin will likely uncover cell-autonomous role of these targets in cardioprotection against I/R and post-infarction injury. The pre-clinical evidence published to date support the concept that enhancing protein quality control mechanisms in the myocardium may be an effective interventional strategy in acute coronary syndromes. 


\section{Ubiquitin Ligases Regulate Mitochondrial Fission and/or Fusion}

Mitochondria are dynamic organelles best known for generating most of the cell's energy and are critical in regulating apoptosis, calcium homeostasis, lipid metabolism, aging, and the production of reactive oxygen species [65]. Maintaining mitochondrial activity and function involves a proper balance of fission and fusion of neighboring mitochondria. Mitochondria fusion results in the mixing of mitochondrial contents, allowing complementation of protein components, mtDNA and distribution of metabolic intermediates. Conversely, division of mitochondria into smaller subunits (fission) increases mitochondrial number and capacity, but may also help segregate damaged mitochondria by selective mitophagy. Disruption of mitochondrial fission and fusion (mitochondrial dynamics) is intimately tied to a cell's regulation of apoptosis is linked to multiple cardiac diseases, including cardiac hypertrophy, heart failure, dilated cardiomyopathy and ischemic heart disease (as recently reviewed [66, 67]). Cardiac ubiquitin ligases and deubiquitinylating enzymes that regulate mitochondria fission and fusion, also appear to have direct roles in the pathophysiology of cardiac disease, including the ubiquitin ligase Siah2 and the de-ubiquitinylating enzymes UBP2 and UBP12.

Recent studies have identified a role for the ubiquitin ligase seven in absentia homolog 2 (Siah2) in the regulation of mitochondrial fission, resulting in the protection of cardiomyocytes against ischemic insult [68]. These studies identified that hypoxia-induced mitochondrial fission is dependent on the mitochondrial scaffolding protein AKAP121 (A kinase anchor protein 1). AKAP121 inhibits the phosphorylation of dynamin-1-like protein (Drp1) and the PKA-independent inhibition of the Drp1-Fis1 interaction (Figure 3B) [68]. Siah2 regulates AKAP121 levels, with cells lacking Siah2 having high AKAP121 levels, resulting in attenuated fission and reduced apoptosis of cardiomyocytes under simulated ischemia conditions in vitro [68]. Myocardial infarction challenge to Siah2 -/- mice results in the reduction of infarct size (i.e. the degree of cardiac cell death) compared to wild type controls, illustrating a role for Siah2 as a regulator of hypoxia-induced mitochondrial fission in ischemic injury [68]. While its is possible that AKAP121 is a substrate of the ubiquitin ligase Siah2, the mechanism by which these proteins interact, including the involvement of ubiquitination or proteasomal degradation, been determined. Despite this, the clinical utility of inhibiting ischemia-induced cell death through manipulation of AKAP121 and/or Siah2 may prove to be an interesting target for treatment of myocardial infarction.

The removing of ubiquitin from substrates by de-ubiquitinylating enzymes may also be involved in regulating mitochondrial fusion in the heart. The de-ubiquitylating enzymes UBP2 and UBP12 recognize ubiquitinated Fzo1, a mitofusion in yeast, resulting in the inhibition of fusion [69]. UBP2 removes the ubiquitin chains from Fzo1 that target it for degradation, whereas UBP12 recognizes chains that stabilize Fzo1 and promote mitochondrial fusion [69]. Although the role of homolog de-ubiquitylating enzymes in the mammalian heart have not currently been identified, these studies in yeast illustrate the importance of how the UPS is fine tuned to both add and remove ubiquitin chains to regulate mitochondrial fission and fusion critical to the health of the heart. 


\section{Ubiquitin ligases involved in Cardiomyocyte Receptor and Gap Junction Turnover}

In addition to regulating sarcomeric protein quality control, signal transduction, and mitochondrial dynamics, ubiquitin ligases can also regulate critical receptors and ion channels in cardiomyocytes, including $\beta$-adrenergic receptors ( $\beta$-ARs), the human ether-àgo-go-related gene (hERG), and connexin 43 . Given the clinical importance of these pathways, delineating the mechanisms by which ubiquitin ligases target and regulate their activity may offer additional insight to alternative therapeutic strategies.

\subsection{MuRF1 and the $\beta$-Adrenergic Receptor}

The importance of the increased sympathetic adrenergic activation in heart failure and ischemic heart disease is most evident by current therapies utilizing $\beta$-adrenergic inhibition as an effective therapy to decrease patient morbidity and mortality. $\beta$-AR stimulation secondary to hypertension not only induces cardiomyocyte growth directly, but can also affect metabolic substrate utilization and prevent cardiac atrophy [70-73], an effect mediated by Atrogin-1 and MuRF1 [13, 14, 74]. Mice treated with 6-OH-DOPA to induce cardiac sympathetic denervation develop cardiac atrophy over a period of thirty days. Denervation-induced atrophic mice show increases in both Atrogin-1 and MuRF1 gene expression as early as 24-hours post 6-OH-DOPA treatment [75]. Blocking $\beta$-AR activity in these mice appears to decrease phosphorylated Akt, leading to increased FOXO transcription factor signaling, which increases ubiquitin ligase activity and induces cardiac atrophy. Conversely, atrophy is attenuated in denervated MuRF1 knockout mice [75]. Noradrenaline specifically activates $\beta 2$-AR signaling that in turn represses MuRF1, demonstrating that the effect of $\beta 2$-AR signaling on cardiomyocyte size is intimately associated with ubiquitin ligase activity [75]. Together, these findings illustrate a novel connection between the ubiquitin ligase activity of MuRF1, denervation and cardiac atrophy. Combined with MuRF1's role at skeletal NMJs [76], it is clear that MuRF1 plays a role in both skeletal and cardiac muscle innervation, highlighting a new therapeutic potential in targeting MuRF1 for treatment of atrophy.

\subsection{Nedd4 and the hERG receptor}

The ubiquitin ligase Nedd4 (neural precursor cell expressed developmentally downregulated protein 4-2) is involved in ion channel protein turnover in the human derived renal epithelial HEK293 cell line. Nedd4, in association with caveolin-3 (Cav3), binds and ubiquitinates hERG channels, targeting them for degradation [77]. Potassium channel $\mathrm{I}_{\mathrm{Kr}}$, encoded by hERG, is critical for cardiac repolarization: current reduction results in delayed repolarization and long QT syndrome [78], whereas current increase results in short QT syndrome [79], both of which cause cardiac arrhythmia. Therefore, maintenance of the $\mathrm{I}_{\mathrm{Kr}}$ ion channel is crucial in maintaining proper cardiac function and preventing arrhythmia [78]. Nedd4-2 can also ubiquitinate the KCNQ1 potassium channel, resulting in KCNQ1's removal from the cell surface, internalization and degradation by the proteasome [80], a reaction that can be counteracted by the de-ubiquitinylating enzyme USP2 [81]. Nedd4-2 specifically interacts with the PY motif of both hERG and KCNQ1 [77, 80, 81], highlighting 
the importance of this motif and potential for further study in other ion channels. Although these findings have been gleaned from in vitro studies, the results lead to the possibility of future in vivo studies focusing on Nedd4's ubiquitin ligase activity in ion channel regulation. Because disruption of hERG channels, due to genetic mutation or drug side-effects, can result in life-threatening arrhythmia $[82,83]$, understanding the mechanism by which Nedd2 facilitates protein turnover at these channels could be critical in developing novel therapeutics for the treatment of arrhythmias.

\subsection{Cardiomyocyte connexin $\mathbf{4 3}$ turnover by an unidentified ubiquitin ligase}

Recent reports have identified that an unidentified ubiquitin ligase is responsible for ubiquitinating phosphorylated connexin 43 (Cx43), resulting it its degradation by the proteasome [84]. Connexin 43 is a cardiac ventricular gap junction protein crucial for cellular communication and cardiac function [85]. Connexin 43's critical role in cardiac rhythms is exemplified in patients suffering from arrhythmogenic cardiomyopathy [86]. When connexin 43 activity is inhibited by mutations, it can lead to the development of an arrhythmogenic cardiomyopathy and sudden death. Adrenergic stimuli increase Cx43 expression via the protein kinase A and MAPK pathways, whereas anti-adrenergic stimuli, like adenosine, cause an opposing affect, promoting phosphorylation of $\mathrm{Cx} 43$ on Serine 368 by protein kinase $\mathrm{C}$ (PKC), subsequent ubiquitination, and proteasomal degradation [84]. Further studies are necessary to determine which ubiquitin ligase is ubiquitinating $\mathrm{Cx} 43$ as well as to understand this mechanism in vivo in order to link connexin turnover to states of cardiac pathology [84].

Altogether, the studies highlighted above, demonstrate novel roles for ubiquitin ligases in the turnover of proteins involved in innervation, ion channels and gap junctions. When combined with what is known about ubiquitin ligase control of sarcomeric and mitochondrial protein turnover, the 'ubiquitous' need for ubiquitin ligases in the heart is abundantly clear.

\section{Ubiquitin ligases involved in Human Hypertrophic Cardiomyopathy}

Recent studies have identified mutations in the MuRF1 ubiquitin ligase as a cause of human hypertrophic cardiomyopathy (HCM) [87, 88]. Sequencing of 302 HCM probands identified 2 missense mutations (p.A48V and p.I130M) and a deletion (p.Q247*) variants in MuRF1 that were absent in 1,090 control subjects; these mutations appeared to be enriched in the Caucasian HCM populations $[87,88]$. While MuRF1 mutations are not commonly mutated in hypertrophic cardiomyopathy populations in these studies, it does appear to be rare cause of clinically significant disease.

Ubiquitin ligases may also be involved in the pathophysiology of HCM in another direct way as well. Both MuRF1 and atrogin-1 have been implicated in targeting both wild type and HCM-causing cardiac myosin binding protein C (cMyBP-C) for degradation [89]. These ubiquitin ligases have been implicated in the rapid removal of cMyBP-C mutant proteins and the turnover of wild type $\mathrm{cMyBP}-\mathrm{C}$ in cell culture and interestingly parallel the rapid degradation of mutant cMyBP-C in humans [89]. Since mutations in cMyBP-C are considered one of the most common causes of hypertrophic cardiomyopathy, these studies 
potentially shed light on one possible reason why MuRF1 mutations cause HCM - their lack of cMyBP-C protein quality control $[87,88]$. These studies also suggest how enhanced protein turnover mechanisms themselves may be detrimental to the heart, since the rapid degradation of mutant cMyBP-C proteins does not allow steady state protein levels to exist, but disease may still occur. Future studies to investigate how HCM occurs when the UPS's protein quality control machinery is hijacked to clear mutant proteins, presuming that the mutant proteins are no longer present to cause problems.

\section{Summary}

As a biological concept alone, the turnover of proteins has remained an integral area of study for many years. The central dogma of biology, where from DNA comes RNA comes protein, highlights the importance of proteins in every facet of life. The UPS and, in particular, ubiquitin ligases are of critical importance in the maintenance of protein quality control. Recent work has emphasized the role of ubiquitin ligases in the heart, both in vitro and in vivo. Whereas previous work emphasized the importance of ubiquitin ligases in the turnover of sarcomeric proteins, the role for these enzymes has become increasingly apparent in the context of mitochondrial dynamics as well as cell signaling and receptor protein turnover. Because these mechanisms are largely conserved between cells, tissues and even species, they are highly applicable to human cardiac health and disease. For example, CHIP's role in attenuating apoptosis after myocardial infarction is dependent on ubiquitination and subsequent degradation of misfolded or unfolded proteins. The continuation of research to elucidate ubiquitin ligase activity in the heart is critical for increasing our knowledge and improving treatment options for the myriad of cardiac diseases that plague humans.

\section{Acknowledgments}

The authors wish to thank Dr. Andrea Portbury and Anasa Sinegal for their valuable comments and editorial assistance.

\section{Non-standard abbreviations}

AChRs

AKAP121

c-Cbl

Cav3

CHIP

cIAP

cMyBP-C

Drp1

E1

E2
Acetylcholine receptors

A-kinase anchor protein 121

Casitas b-lineage lymphoma

cavelin 3

c-terminus of Hsp70-interacting protein

cellular inhibitor of apoptosis

cardiac myosin binding protein $\mathrm{C}$

dynamin-1-like protein

ubiquitin-activating enzyme

ubiquitin-conjugating enzyme 


\begin{tabular}{|c|c|}
\hline $\mathbf{E 3}$ & ubiquitin ligase \\
\hline Fbxl22 & F-box and leucine-rich repeat protein 22 \\
\hline Fis1 & fission 1 \\
\hline hERG & human ether-à-go-go-related gene \\
\hline MAFBx & atrogin-1/muscle atrophy F-box \\
\hline MDM2 & murine double minute 2 \\
\hline Mfn-1 (-2) & mitofusin-1(-2) \\
\hline OMM & outer mitochondrial membrane \\
\hline $\operatorname{MuRF1}(2,3)$ & muscle ring finger $-1(-2,-3)$ \\
\hline Nedd4-2 & $\begin{array}{l}\text { neural precursor cell expressed developmentally down-regulated protein } \\
4-2\end{array}$ \\
\hline Opa1 & optic atrophy 1 \\
\hline Siah1a/2 & Seven In Absentia Homolog-1a/2 \\
\hline PINK1 & PTEN-induced putative kinase protein 1 \\
\hline UBE3A/E6AP & ubiquitin-protein ligase E3A \\
\hline
\end{tabular}

\section{References}

1. Willis MS, Schisler JC, Portbury AL, Patterson C. Build it up-Tear it down: protein quality control in the cardiac sarcomere. Cardiovasc Res. 2009; 81:439-48. [PubMed: 18974044]

2. Rock KL, Gramm C, Rothstein L, Clark K, Stein R, Dick L, et al. Inhibitors of the proteasome block the degradation of most cell proteins and the generation of peptides presented on MHC class I molecules. Cell. 1994; 78:761-71. [PubMed: 8087844]

3. Baehrecke EH. Autophagy: dual roles in life and death? Nat Rev Mol Cell Biol. 2005; 6:505-10. [PubMed: 15928714]

4. Lardeux BR, Mortimore GE. Amino acid and hormonal control of macromolecular turnover in perfused rat liver. Evidence for selective autophagy. J Biol Chem. 1987; 262:14514-9. [PubMed: 2444587]

5. Willis MS, Patterson C. Into the heart: the emerging role of the ubiquitin-proteasome system. J Mol Cell Cardiol. 2006; 41:567-79. [PubMed: 16949602]

6. Willis MS, Townley-Tilson WH, Kang EY, Homeister JW, Patterson C. Sent to destroy: the ubiquitin proteasome system regulates cell signaling and protein quality control in cardiovascular development and disease. Circulation research. 2010; 106:463-78. [PubMed: 20167943]

7. Spaich S, Will RD, Just S, Spaich S, Kuhn C, Frank D, et al. F-box and leucine-rich repeat protein 22 is a cardiac-enriched F-box protein that regulates sarcomeric protein turnover and is essential for maintenance of contractile function in vivo. Circulation research. 2012; 111:1504-16. [PubMed: 22972877]

8. Samarel AM, Parmacek MS, Magid NM, Decker RS, Lesch M. Protein synthesis and degradation during starvation-induced cardiac atrophy in rabbits. Circulation research. 1987; 60:933-41. [PubMed: 3594760]

9. Coleman PS, Parmacek MS, Lesch M, Samarel AM. Protein synthesis and degradation during regression of thyroxine-induced cardiac hypertrophy. J Mol Cell Cardiol. 1989; 21:911-25. [PubMed: 2530358] 
10. Parmacek MS, Magid NM, Lesch M, Decker RS, Samarel AM. Cardiac protein synthesis and degradation during thyroxine-induced left ventricular hypertrophy. Am J Physiol. 1986; 251:C727-36. [PubMed: 2946236]

11. Arya R, Kedar V, Hwang JR, McDonough H, Li HH, Taylor J, et al. Muscle ring finger protein-1 inhibits PKC \{epsilon $\}$ activation and prevents cardiomyocyte hypertrophy. J Cell Biol. 2004; 167:1147-59. [PubMed: 15596539]

12. Willis MS, Ike C, Li L, Wang DZ, Glass DJ, Patterson C. Muscle ring finger 1, but not muscle ring finger 2, regulates cardiac hypertrophy in vivo. Circulation research. 2007; 100:456-9. [PubMed: 17272810]

13. Baskin KKC, Wenhao, Salazar Rebecca, Taegtmeyer Heinrich. Abstract 3210: The Ubiquitin Ligase Atrogin-1, but Not MuRF1, is Required for Atrophic Remodeling of the Heart. Circulation. 2009:120. [PubMed: 19808456]

14. Willis MS, Rojas M, Li L, Selzman CH, Tang RH, Stansfield WE, et al. Muscle ring finger 1 mediates cardiac atrophy in vivo. Am J Physiol Heart Circ Physiol. 2009; 296:H997-H1006. [PubMed: 19168726]

15. Le NT, Takei Y, Shishido T, Woo CH, Chang E, Heo KS, et al. p90RSK targets the ERK5-CHIP ubiquitin E3 ligase activity in diabetic hearts and promotes cardiac apoptosis and dysfunction. Circulation research. 2012; 110:536-50. [PubMed: 22267842]

16. Zhang C, Xu Z, He XR, Michael LH, Patterson C. CHIP, a cochaperone/ubiquitin ligase that regulates protein quality control, is required for maximal cardioprotection after myocardial infarction in mice. American journal of physiology Heart and circulatory physiology. 2005; 288:H2836-42. [PubMed: 15665051]

17. Toth A, Nickson P, Qin LL, Erhardt P. Differential regulation of cardiomyocyte survival and hypertrophy by MDM2, an E3 ubiquitin ligase. J Biol Chem. 2006; 281:3679-89. [PubMed: 16339144]

18. Hwang JR, Zhang C, Patterson C. C-terminus of heat shock protein 70-interacting protein facilitates degradation of apoptosis signal-regulating kinase 1 and inhibits apoptosis signalregulating kinase 1-dependent apoptosis. Cell Stress Chaperones. 2005; 10:147-56. [PubMed: 16038411]

19. Preedy VR, Smith DM, Kearney NF, Sugden PH. Rates of protein turnover in vivo and in vitro in ventricular muscle of hearts from fed and starved rats. The Biochemical journal. 1984; 222:395400. [PubMed: 6206849]

20. Mostow WR, Ferguson AG, Lesch M, Decker RS, Samarel AM. Nonrandom turnover of actin and tubulin in cultured rabbit cardiac fibroblasts. Am J Physiol. 1988; 255:C202-13. [PubMed: 3407765]

21. Eble DM, Spragia ML, Ferguson AG, Samarel AM. Sarcomeric myosin heavy chain is degraded by the proteasome. Cell Tissue Res. 1999; 296:541-8. [PubMed: 10370141]

22. Bodine SC, Latres E, Baumhueter S, Lai VK, Nunez L, Clarke BA, et al. Identification of ubiquitin ligases required for skeletal muscle atrophy. Science. 2001; 294:1704-8. [PubMed: 11679633]

23. Kim HT, Kim KP, Lledias F, Kisselev AF, Scaglione KM, Skowyra D, et al. Certain pairs of ubiquitin-conjugating enzymes (E2s) and ubiquitin-protein ligases (E3s) synthesize nondegradable forked ubiquitin chains containing all possible isopeptide linkages. J Biol Chem. 2007; 282:17375-86. [PubMed: 17426036]

24. Mohapatra B, Jimenez S, Lin JH, Bowles KR, Coveler KJ, Marx JG, et al. Mutations in the muscle LIM protein and alpha-actinin-2 genes in dilated cardiomyopathy and endocardial fibroelastosis. Mol Genet Metab. 2003; 80:207-15. [PubMed: 14567970]

25. Faulkner G, Lanfranchi G, Valle G. Telethonin and other new proteins of the Z-disc of skeletal muscle. IUBMB Life. 2001; 51:275-82. [PubMed: 11699871]

26. Gupta V, Discenza M, Guyon JR, Kunkel LM, Beggs AH. alpha-Actinin-2 deficiency results in sarcomeric defects in zebrafish that cannot be rescued by alpha-actinin-3 revealing functional differences between sarcomeric isoforms. FASEB J. 2012; 26:1892-908. [PubMed: 22253474]

27. Chiu C, Bagnall RD, Ingles J, Yeates L, Kennerson M, Donald JA, et al. Mutations in alphaactinin-2 cause hypertrophic cardiomyopathy: a genome-wide analysis. J Am Coll Cardiol. 2010; 55:1127-35. [PubMed: 20022194] 
28. Fujita M, Mitsuhashi H, Isogai S, Nakata T, Kawakami A, Nonaka I, et al. Filamin C plays an essential role in the maintenance of the structural integrity of cardiac and skeletal muscles, revealed by the medaka mutant zacro. Dev Biol. 2012; 361:79-89. [PubMed: 22020047]

29. Selcen D. Myofibrillar myopathies. Curr Opin Neurol. 2008; 21:585-9. [PubMed: 18769253]

30. Selcen D, Carpen O. The Z-disk diseases. Adv Exp Med Biol. 2008; 642:116-30. [PubMed: 19181098]

31. Rafiq K, Guo J, Vlasenko L, Guo X, Kolpakov MA, Sanjay A, et al. c-Cbl ubiquitin ligase regulates focal adhesion protein turnover and myofibril degeneration induced by neutrophil protease cathepsin G. J Biol Chem. 2012; 287:5327-39. [PubMed: 22203672]

32. Eble DM, Strait JB, Govindarajan G, Lou J, Byron KL, Samarel AM. Endothelin-induced cardiac myocyte hypertrophy: role for focal adhesion kinase. Am J Physiol Heart Circ Physiol. 2000; 278:H1695-707. [PubMed: 10775151]

33. Hakim ZS, DiMichele LA, Rojas M, Meredith D, Mack CP, Taylor JM. FAK regulates cardiomyocyte survival following ischemia/reperfusion. J Mol Cell Cardiol. 2009; 46:241-8. [PubMed: 19028502]

34. Cheng Z, DiMichele LA, Hakim ZS, Rojas M, Mack CP, Taylor JM. Targeted focal adhesion kinase activation in cardiomyocytes protects the heart from ischemia/reperfusion injury. Arterioscler Thromb Vasc Biol. 2012; 32:924-33. [PubMed: 22383703]

35. Doherty JT, Conlon FL, Mack CP, Taylor JM. Focal adhesion kinase is essential for cardiac looping and multichamber heart formation. Genesis. 2010; 48:492-504. [PubMed: 20572259]

36. Zajac B, Hakim ZS, Cameron MV, Smithies O, Taylor JM. Quantification of myocyte chemotaxis: a role for FAK in regulating directional motility. Methods Mol Biol. 2012; 843:111-23. [PubMed: 22222526]

37. Warren SA, Briggs LE, Zeng H, Chuang J, Chang EI, Terada R, et al. Myosin light chain phosphorylation is critical for adaptation to cardiac stress. Circulation. 2012; 126:2575-88. [PubMed: 23095280]

38. Minicucci MF, Azevedo PS, Polegato BF, Paiva SA, Zornoff LA. Heart failure after myocardial infarction: clinical implications and treatment. Clinical cardiology. 2011; 34:410-4. [PubMed: 21688276]

39. Thygesen K, Alpert JS, Jaffe AS, Simoons ML, Chaitman BR, White HD, et al. Third universal definition of myocardial infarction. Journal of the American College of Cardiology. 2012; 60:1581-98. [PubMed: 22958960]

40. Ma Y, Halade GV, Lindsey ML. Extracellular matrix and fibroblast communication following myocardial infarction. Journal of cardiovascular translational research. 2012; 5:848-57. [PubMed: 22926488]

41. Portbury AL, Ronnebaum SM, Zungu M, Patterson C, Willis MS. Back to your heart: ubiquitin proteasome system-regulated signal transduction. J Mol Cell Cardiol. 2012; 52:526-37. [PubMed: 22085703]

42. Decker RS, Wildenthal K. Lysosomal alterations in hypoxic and reoxygenated hearts. I. Ultrastructural and cytochemical changes. The American journal of pathology. 1980; 98:425-44. [PubMed: 7355988]

43. Wildenthal K, Decker RS. The role of lysosomes in the heart. Advances in myocardiology. 1980; 2:349-58. [PubMed: 7423050]

44. Rifki OF, Hill JA. Cardiac autophagy: good with the bad. J Cardiovasc Pharmacol. 2012; 60:24852. [PubMed: 22743635]

45. Dong Y, Undyala VV, Gottlieb RA, Mentzer RM Jr, Przyklenk K. Autophagy: definition, molecular machinery, and potential role in myocardial ischemia-reperfusion injury. Journal of cardiovascular pharmacology and therapeutics. 2010; 15:220-30. [PubMed: 20595626]

46. Gottlieb RA, Mentzer RM. Autophagy during cardiac stress: joys and frustrations of autophagy. Annual review of physiology. 2010; 72:45-59.

47. Gustafsson AB, Gottlieb RA. Autophagy in ischemic heart disease. Circulation research. 2009; 104:150-8. [PubMed: 19179668]

48. Chen Y, Dorn GW 2nd. PINK1-phosphorylated mitofusin 2 is a Parkin receptor for culling damaged mitochondria. Science. 2013; 340:471-5. [PubMed: 23620051] 
49. Huang C, Andres AM, Ratliff EP, Hernandez G, Lee P, Gottlieb RA. Preconditioning involves selective mitophagy mediated by Parkin and p62/SQSTM1. PloS one. 2011; 6:e20975. [PubMed: 21687634]

50. Boncoraglio A, Minoia M, Carra S. The family of mammalian small heat shock proteins (HSPBs): implications in protein deposit diseases and motor neuropathies. The international journal of biochemistry \& cell biology. 2012; 44:1657-69. [PubMed: 22484489]

51. Cornelussen RN, Vanagt WY, Prinzen FW, Snoeckx LH. Proteins involved in salvage of the myocardium. Advances in experimental medicine and biology. 2003; 543:277-91. [PubMed: 14713129]

52. Knowlton AA, Kapadia S, Torre-Amione G, Durand JB, Bies R, Young J, et al. Differential expression of heat shock proteins in normal and failing human hearts. Journal of molecular and cellular cardiology. 1998; 30:811-8. [PubMed: 9602430]

53. Willis MS, Patterson C. Hold me tight: Role of the heat shock protein family of chaperones in cardiac disease. Circulation. 2010; 122:1740-51. [PubMed: 20975010]

54. Delogu G, Signore M, Mechelli A, Famularo G. Heat shock proteins and their role in heart injury. Current opinion in critical care. 2002; 8:411-6. [PubMed: 12357108]

55. Ballinger CA, Connell P, Wu Y, Hu Z, Thompson LJ, Yin LY, et al. Identification of CHIP, a novel tetratricopeptide repeat-containing protein that interacts with heat shock proteins and negatively regulates chaperone functions. Molecular and cellular biology. 1999; 19:4535-45. [PubMed: 10330192]

56. Connell P, Ballinger CA, Jiang J, Wu Y, Thompson LJ, Hohfeld J, et al. The co-chaperone CHIP regulates protein triage decisions mediated by heat-shock proteins. Nature cell biology. 2001; 3:93-6.

57. Jiang J, Ballinger CA, Wu Y, Dai Q, Cyr DM, Hohfeld J, et al. CHIP is a U-box-dependent E3 ubiquitin ligase: identification of Hsc70 as a target for ubiquitylation. The Journal of biological chemistry. 2001; 276:42938-44. [PubMed: 11557750]

58. Richardson PJ, Patel VB, Preedy VR. Alcohol and the myocardium. Novartis Found Symp. 1998; 216:35-45. discussion-50. [PubMed: 9949786]

59. Rylander MN, Feng Y, Bass J, Diller KR. Thermally induced injury and heat-shock protein expression in cells and tissues. Ann N Y Acad Sci. 2005; 1066:222-42. [PubMed: 16533928]

60. Li F, Xie P, Fan Y, Zhang H, Zheng L, Gu D, et al. C terminus of Hsc70-interacting protein promotes smooth muscle cell proliferation and survival through ubiquitin-mediated degradation of FoxO1. The Journal of biological chemistry. 2009; 284:20090-8. [PubMed: 19483080]

61. Xie P, Fan Y, Zhang H, Zhang Y, She M, Gu D, et al. CHIP represses myocardin-induced smooth muscle cell differentiation via ubiquitin-mediated proteasomal degradation. Molecular and cellular biology. 2009; 29:2398-408. [PubMed: 19237536]

62. Yang K, Zhang TP, Tian C, Jia LX, Du J, Li HH. Carboxyl terminus of heat shock protein 70interacting protein inhibits angiotensin II-induced cardiac remodeling. American journal of hypertension. 2012; 25:994-1001. [PubMed: 22717542]

63. Naito AT, Okada S, Minamino T, Iwanaga K, Liu ML, Sumida T, et al. Promotion of CHIPmediated p53 degradation protects the heart from ischemic injury. Circulation research. 2010; 106:1692-702. [PubMed: 20413784]

64. Willis MS, Min JN, Wang S, McDonough H, Lockyer P, Wadosky KM, et al. Carboxyl terminus of Hsp70-interacting protein (CHIP) is required to modulate cardiac hypertrophy and attenuate autophagy during exercise. Cell biochemistry and function. 2013

65. Bayeva M, Gheorghiade M, Ardehali H. Mitochondria as a therapeutic target in heart failure. J Am Coll Cardiol. 2013; 61:599-610. [PubMed: 23219298]

66. Zungu M, Schisler J, Willis MS. All the little pieces. -Regulation of mitochondrial fusion and fission by ubiquitin and small ubiquitin-like modifer and their potential relevance in the heart. Circ J. 2011; 75:2513-21. [PubMed: 22001293]

67. Dorn GW II. Mitochondrial dynamism and cardiac fate. Circ J. 2013; 77:1370-9. [PubMed: 23615052] 
68. Kim H, Scimia MC, Wilkinson D, Trelles RD, Wood MR, Bowtell D, et al. Fine-tuning of Drp1/ Fis1 availability by AKAP121/Siah2 regulates mitochondrial adaptation to hypoxia. Mol Cell. 2011; 44:532-44. [PubMed: 22099302]

69. Anton F, Dittmar G, Langer T, Escobar-Henriques M. Two deubiquitylases act on mitofusin and regulate mitochondrial fusion along independent pathways. Mol Cell. 2013; 49:487-98. [PubMed: 23317502]

70. Zhu M, Zhao W, Vazquez N, Mitroka JG. Analysis of low level radioactive metabolites in biological fluids using high-performance liquid chromatography with microplate scintillation counting: method validation and application. J Pharm Biomed Anal. 2005; 39:233-45. [PubMed: 15899570]

71. Ryall JG, Sillence MN, Lynch GS. Systemic administration of beta2-adrenoceptor agonists, formoterol and salmeterol, elicit skeletal muscle hypertrophy in rats at micromolar doses. $\mathrm{Br} \mathrm{J}$ Pharmacol. 2006; 147:587-95. [PubMed: 16432501]

72. Tevaearai HT, Eckhart AD, Walton GB, Keys JR, Wilson K, Koch WJ. Myocardial gene transfer and overexpression of beta2-adrenergic receptors potentiates the functional recovery of unloaded failing hearts. Circulation. 2002; 106:124-9. [PubMed: 12093781]

73. Birks EJ, Tansley PD, Hardy J, George RS, Bowles CT, Burke M, et al. Left ventricular assist device and drug therapy for the reversal of heart failure. N Engl J Med. 2006; 355:1873-84. [PubMed: 17079761]

74. Zhang W, Yano N, Deng M, Mao Q, Shaw SK, Tseng YT. beta-Adrenergic receptor-PI3K signaling crosstalk in mouse heart: elucidation of immediate downstream signaling cascades. PLoS One. 2011; 6:e26581. [PubMed: 22028912]

75. Zaglia T, Milan G, Franzoso M, Bertaggia E, Pianca N, Piasentini E, et al. Cardiac sympathetic neurons provide trophic signal to the heart via beta2-adrenoceptor-dependent regulation of proteolysis. Cardiovasc Res. 2013; 97:240-50. [PubMed: 23090606]

76. Rudolf R, Bogomolovas J, Strack S, Choi KR, Khan MM, Wagner A, et al. Regulation of nicotinic acetylcholine receptor turnover by MuRF1 connects muscle activity to endo/lysosomal and atrophy pathways. Age (Dordr). 2012

77. Guo J, Wang T, Li X, Shallow H, Yang T, Li W, et al. Cell surface expression of human ether-ago-go-related gene (hERG) channels is regulated by caveolin-3 protein via the ubiquitin ligase Nedd4-2. J Biol Chem. 2012; 287:33132-41. [PubMed: 22879586]

78. Keating MT, Sanguinetti MC. Molecular and cellular mechanisms of cardiac arrhythmias. Cell. 2001; 104:569-80. [PubMed: 11239413]

79. Brugada R, Hong K, Dumaine R, Cordeiro J, Gaita F, Borggrefe M, et al. Sudden death associated with short-QT syndrome linked to mutations in HERG. Circulation. 2004; 109:30-5. [PubMed: 14676148]

80. Jespersen T, Membrez M, Nicolas CS, Pitard B, Staub O, Olesen SP, et al. The KCNQ1 potassium channel is down-regulated by ubiquitylating enzymes of the Nedd4/Nedd4-like family. Cardiovasc Res. 2007; 74:64-74. [PubMed: 17289006]

81. Krzystanek K, Rasmussen HB, Grunnet M, Staub O, Olesen SP, Abriel H, et al. Deubiquitylating enzyme USP2 counteracts Nedd4-2-mediated downregulation of KCNQ1 potassium channels. Heart Rhythm. 2012; 9:440-8. [PubMed: 22024150]

82. Sanguinetti MC, Tristani-Firouzi M. hERG potassium channels and cardiac arrhythmia. Nature. 2006; 440:463-9. [PubMed: 16554806]

83. Dolmatova E, Mahida S, Ellinor PT, Lubitz SA. Genetic etiology and evaluation of sudden cardiac death. Curr Cardiol Rep. 2013; 15:389. [PubMed: 23812838]

84. Popolo A, Morello S, Sorrentino R, Pinto A. Antiadrenergic effect of adenosine involves connexin 43 turn-over in H9c2 cells. Eur J Pharmacol. 2013

85. Srisakuldee W, Nickel BE, Fandrich RR, Jiang ZS, Kardami E. Administration of FGF-2 to the heart stimulates connexin-43 phosphorylation at protein kinase $\mathrm{C}$ target sites. Cell Commun Adhes. 2006; 13:13-9. [PubMed: 16613776]

86. Gillet L, Shy D, Abriel H. NaV1.5 and interacting proteins in human arrhythmogenic cardiomyopathy. Future Cardiol. 2013; 9:467-70. [PubMed: 23834686] 
87. Chen SN, Czernuszewicz G, Tan Y, Lombardi R, Jin J, Willerson JT, et al. Human Molecular Genetic and Functional Studies Identify TRIM63, Encoding Muscle RING Finger Protein 1, as a Novel Gene for Human Hypertrophic Cardiomyopathy. Circulation research. 2012

88. Chen SN, Rodriguez G, Czernuszewicz G, UJ, Jin J, Marian AJ. TRIM63, Encoding MuRF1, is a Novel Gene for Human Hypertrophic Cardiomyopathy. Circulation. 2010; 122:A21194.

89. Mearini G, Gedicke C, Schlossarek S, Witt CC, Kramer E, Cao P, et al. Atrogin-1 and MuRF1 regulate cardiac MyBP-C levels via different mechanisms. Cardiovasc Res. 2010; 85:357-66. [PubMed: 19850579]

90. Li HH, Willis MS, Lockyer P, Miller N, McDonough H, Glass DJ, et al. Atrogin-1 inhibits Aktdependent cardiac hypertrophy in mice via ubiquitin-dependent coactivation of Forkhead proteins. J Clin Invest. 2007; 117:3211-23. [PubMed: 17965779]

91. Schisler JC, Willis MS, Patterson C. You spin me round: MaFBx/Atrogin-1 feeds forward on FOXO transcription factors (like a record). Cell Cycle. 2008; 7:440-3. [PubMed: 18235241]

92. Spence J, Sadis S, Haas AL, Finley D. A ubiquitin mutant with specific defects in DNA repair and multiubiquitination. Mol Cell Biol. 1995; 15:1265-73. [PubMed: 7862120]

93. Torres MP, Lee MJ, Ding F, Purbeck C, Kuhlman B, Dokholyan NV, et al. G Protein Monoubiquitination by the Rsp5 Ubiquitin Ligase. J Biol Chem. 2009; 284:8940-50. [PubMed: 19176477]

94. Shimokawa N, Okada J, Haglund K, Dikic I, Koibuchi N, Miura M. Past-A, a novel protonassociated sugar transporter, regulates glucose homeostasis in the brain. J Neurosci. 2002; 22:9160-5. [PubMed: 12417639]

95. Leithe E, Rivedal E. Ubiquitination and down-regulation of gap junction protein connexin-43 in response to 12-O-tetradecanoylphorbol 13-acetate treatment. J Biol Chem. 2004; 279:50089-96. [PubMed: 15371442]

96. Leithe E, Rivedal E. Epidermal growth factor regulates ubiquitination, internalization and proteasome-dependent degradation of connexin 43. J Cell Sci. 2004; 117:1211-20. [PubMed: 14970263]

97. Huang H, Joazeiro CA, Bonfoco E, Kamada S, Leverson JD, Hunter T. The inhibitor of apoptosis, cIAP2, functions as a ubiquitin-protein ligase and promotes in vitro monoubiquitination of caspases 3 and 7. J Biol Chem. 2000; 275:26661-4. [PubMed: 10862606]

98. Jennissen HP, Laub M. Ubiquitin-calmodulin conjugating activity from cardiac muscle. Biol Chem Hoppe Seyler. 1988; 369:1325-30. [PubMed: 2853950]

99. Platta HW, Abrahamsen H, Thoresen SB, Stenmark H. Nedd4-dependent lysine-11-linked polyubiquitination of the tumour suppressor Beclin 1. The Biochemical journal. 2012; 441:399406. [PubMed: 21936852]

100. Alberti S, Esser C, Hohfeld J. BAG-1--a nucleotide exchange factor of Hsc70 with multiple cellular functions. Cell stress \& chaperones. 2003; 8:225-31. [PubMed: 14984055]

101. Takayama S, Bimston DN, Matsuzawa S, Freeman BC, Aime-Sempe C, Xie Z, et al. BAG-1 modulates the chaperone activity of Hsp70/Hsc70. The EMBO journal. 1997; 16:4887-96. [PubMed: 9305631]

102. Gurusamy N, Lekli I, Gorbunov NV, Gherghiceanu M, Popescu LM, Das DK. Cardioprotection by adaptation to ischaemia augments autophagy in association with BAG-1 protein. Journal of cellular and molecular medicine. 2009; 13:373-87. [PubMed: 18793351]

103. Galigniana MD, Harrell JM, Housley PR, Patterson C, Fisher SK, Pratt WB. Retrograde transport of the glucocorticoid receptor in neurites requires dynamic assembly of complexes with the protein chaperone hsp90 and is linked to the CHIP component of the machinery for proteasomal degradation. Brain research Molecular brain research. 2004; 123:27-36. [PubMed: 15046863]

104. Meacham GC, Patterson C, Zhang W, Younger JM, Cyr DM. The Hsc70 co-chaperone CHIP targets immature CFTR for proteasomal degradation. Nature cell biology. 2001; 3:100-5.

105. Dickey CA, Kamal A, Lundgren K, Klosak N, Bailey RM, Dunmore J, et al. The high-affinity HSP90-CHIP complex recognizes and selectively degrades phosphorylated tau client proteins. The Journal of clinical investigation. 2007; 117:648-58. [PubMed: 17304350] 
106. Al-Ramahi I, Lam YC, Chen HK, de Gouyon B, Zhang M, Perez AM, et al. CHIP protects from the neurotoxicity of expanded and wild-type ataxin-1 and promotes their ubiquitination and degradation. The Journal of biological chemistry. 2006; 281:26714-24. [PubMed: 16831871]

107. Zhou P, Fernandes N, Dodge IL, Reddi AL, Rao N, Safran H, et al. ErbB2 degradation mediated by the co-chaperone protein CHIP. The Journal of biological chemistry. 2003; 278:13829-37. [PubMed: 12574167]

108. Kedar V, McDonough H, Arya R, Li HH, Rockman HA, Patterson C. Muscle-specific RING finger 1 is a bona fide ubiquitin ligase that degrades cardiac troponin I. Proc Natl Acad Sci U S A. 2004; 101:18135-40. [PubMed: 15601779]

109. Li HH, Du J, Fan YN, Zhang ML, Liu DP, Li L, et al. The ubiquitin ligase MuRF1 protects against cardiac ischemia/reperfusion injury by its proteasome-dependent degradation of phosphoc-Jun. Am J Pathol. 2011; 178:1043-58. [PubMed: 21356357]

110. Willis MS, Schisler JC, Li L, Rodriguez JE, Hilliard EG, Charles PC, et al. Cardiac muscle ring finger-1 increases susceptibility to heart failure in vivo. Circulation research. 2009; 105:80-8. [PubMed: 19498199]

111. Willis MS, Wadosky KM, Rodriguez JE, Schisler JC, Lockyer P, Hilliard EG, et al. Muscle ring finger 1 and muscle ring finger 2 are necessary but functionally redundant during developmental cardiac growth and regulate E2F1-mediated gene expression in vivo. Cell Biochem Funct. 2013

112. Fielitz J, van Rooij E, Spencer JA, Shelton JM, Latif S, van der Nagel R, et al. Loss of musclespecific RING-finger 3 predisposes the heart to cardiac rupture after myocardial infarction. Proc Natl Acad Sci U S A. 2007; 104:4377-82. [PubMed: 17360532]

113. Ni YG, Berenji K, Wang N, Oh M, Sachan N, Dey A, et al. Foxo transcription factors blunt cardiac hypertrophy by inhibiting calcineurin signaling. Circulation. 2006; 114:1159-68. [PubMed: 16952979]

114. Li HH, Kedar V, Zhang C, McDonough H, Arya R, Wang DZ, et al. Atrogin-1/muscle atrophy Fbox inhibits calcineurin-dependent cardiac hypertrophy by participating in an SCF ubiquitin ligase complex. J Clin Invest. 2004; 114:1058-71. [PubMed: 15489953]

115. Xie P, Guo S, Fan Y, Zhang H, Gu D, Li H. Atrogin-1/MAFbx enhances simulated ischemia/ reperfusion-induced apoptosis in cardiomyocytes through degradation of MAPK phosphatase-1 and sustained JNK activation. J Biol Chem. 2009; 284:5488-96. [PubMed: 19117950]

116. Schisler JC, Rubel CE, Zhang C, Lockyer P, Cyr DM, Patterson C. CHIP protects against cardiac pressure overload through regulation of AMPK. Journal of Clinical Investigation. 2013

117. McDonough H, Patterson C. CHIP: a link between the chaperone and proteasome systems. Cell Stress Chaperones. 2003; 8:303-8. [PubMed: 15115282]

118. Zhao B, Sun G, Feng G, Duan W, Zhu X, Chen S, et al. Carboxy terminus of heat shock protein (HSP) 70-interacting protein (CHIP) inhibits HSP70 in the heart. J Physiol Biochem. 2012; 68:485-91. [PubMed: 22456997]

119. Woo CH, Le NT, Shishido T, Chang E, Lee H, Heo KS, et al. Novel role of C terminus of Hsc70interacting protein (CHIP) ubiquitin ligase on inhibiting cardiac apoptosis and dysfunction via regulating ERK5-mediated degradation of inducible cAMP early repressor. FASEB J. 2010; 24:4917-28. [PubMed: 20724525]

120. Tian LF, Li HY, Jin BF, Pan X, Man JH, Zhang PJ, et al. MDM2 interacts with and downregulates a sarcomeric protein, TCAP. Biochem Biophys Res Commun. 2006; 345:355-61. [PubMed: 16678796]

121. Haupt Y, Maya R, Kazaz A, Oren M. Mdm2 promotes the rapid degradation of p53. Nature. 1997; 387:296-9. [PubMed: 9153395]

122. Balasubramanian S, Mani S, Shiraishi H, Johnston RK, Yamane K, Willey CD, et al. Enhanced ubiquitination of cytoskeletal proteins in pressure overloaded myocardium is accompanied by changes in specific E3 ligases. J Mol Cell Cardiol. 2006; 41:669-79. [PubMed: 16928382]

123. Potts MB, Vaughn AE, McDonough H, Patterson C, Deshmukh M. Reduced Apaf-1 levels in cardiomyocytes engage strict regulation of apoptosis by endogenous XIAP. J Cell Biol. 2005; 171:925-30. [PubMed: 16344307]

124. Witt CC, Witt SH, Lerche S, Labeit D, Back W, Labeit S. Cooperative control of striated muscle mass and metabolism by MuRF1 and MuRF2. EMBO J. 2008; 27:350-60. [PubMed: 18157088] 
125. Witt SH, Granzier H, Witt CC, Labeit S. MURF-1 and MURF-2 target a specific subset of myofibrillar proteins redundantly: towards understanding MURF-dependent muscle ubiquitination. J Mol Biol. 2005; 350:713-22. [PubMed: 15967462]

126. Lange S, Xiang F, Yakovenko A, Vihola A, Hackman P, Rostkova E, et al. The kinase domain of titin controls muscle gene expression and protein turnover. Science. 2005; 308:1599-603. [PubMed: 15802564]

127. Fielitz J, Kim MS, Shelton JM, Latif S, Spencer JA, Glass DJ, et al. Myosin accumulation and striated muscle myopathy result from the loss of muscle RING finger 1 and 3. J Clin Invest. 2007; 117:2486-95. [PubMed: 17786241]

128. Rosser MF, Washburn E, Muchowski PJ, Patterson C, Cyr DM. Chaperone functions of the E3 ubiquitin ligase CHIP. J Biol Chem. 2007; 282:22267-77. [PubMed: 17545168] 


\section{Highlights}

- Sarcomere protein turnover in the heart is maintained by the ubiquitin proteasome system (UPS)

- Dysregulation of protein turnover occurs in cardiac hypertrophy, atrophy, and heart failure

- Ubiquitin ligases (E3) interact with specific sarcomere protein substrate(s) to mediate turnover

- Cardiomyocyte E3s regulate cell signaling that controls cell functions including cell death/apoptosis

- Cardiomyocyte E3 activities depend on disease context and substrate presence and/or quality 

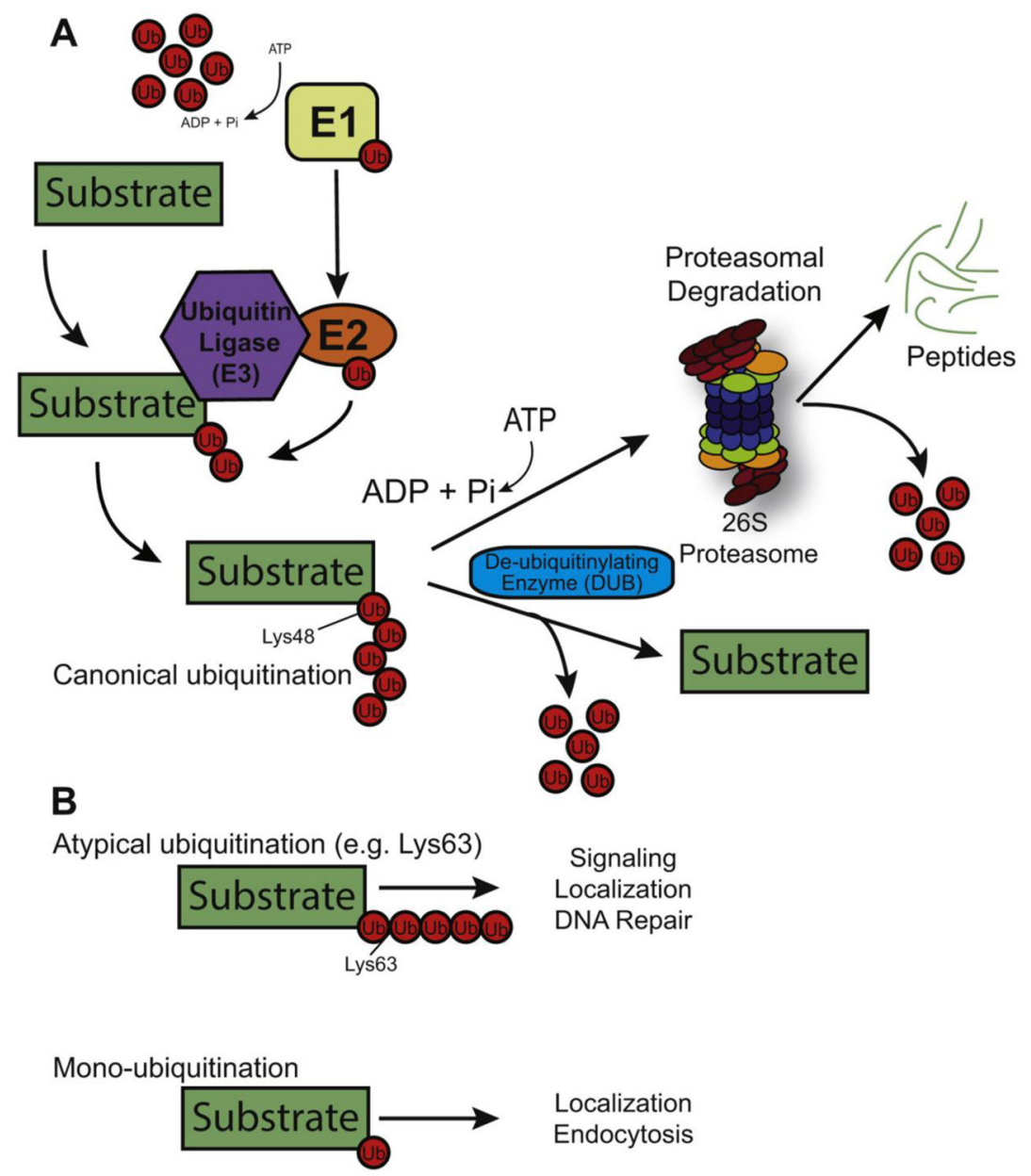

Figure 1. The ubiquitin-proteasome system

A. Post-translational modification of target proteins is necessary for degradation to occur via the UPS. Ubiquitin, a 76-amino acid moiety, is the star player in these modifications: E1 enzymes activate free ubiquitin by using energy from ATP to generate a high-energy thioester bond with ubiquitin. Activated ubiquitin is then transferred to an E2 enzyme, which then interacts with an E3 enzyme. Ubiquitin ligases finally transfer this ubiquitin to a lysine residue in the target protein. Once mono-ubiquitination occurs, this ubiquitin acts as an acceptor for the addition of multiple ubiquitin molecules via isopeptide linkages, resulting in polyubiquitin chains. B. Ubiquitin has seven lysine residues available for polyubiquitin chains to be formed (Lys6, Lys11, Lys27, Lys29, Lys33, Lys48, Lys63), though addition at Lys48 is considered the canonical polyubiquitin chain for protein degradation via the proteasome. Polyubiquitination at Lys63 has been shown to modify target protein activity [90] such as Atrogin-1's role in regulating FOXO [91], regulate physiological cardiac hypertrophy [90] and play a role in DNA repair mechanisms [92]. Other noncanonical lysines have not yet been implicated in specific functional roles. Similarly, monoubiquitination does not lead directly to degradation and instead can alter activity by tagging proteins for shuttle to other cellular compartments [93] or play a role in numerous aspects of signaling pathways, including receptor activity [94], cell-to-cell electrical coupling [95, 96], apoptosis [97] and calcium regulation [98]. Recent studies have also identified that Lys63 ubiquitination targets proteins for autophagy-lysosomal degradation through poly-ubiquitination of beclin-1 [99]. 
A

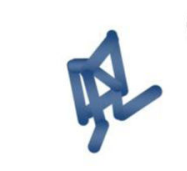

Folded protein

\section{Cell stress}

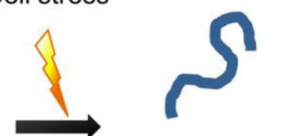

Unfolded protein

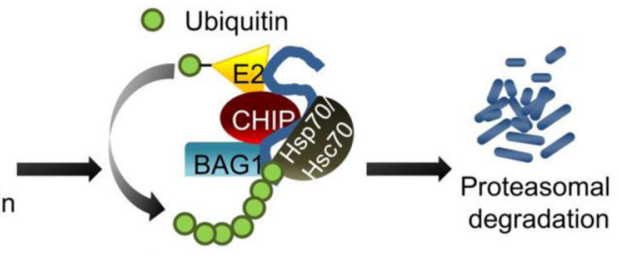

CHIP-mediated

protein ubiquitination

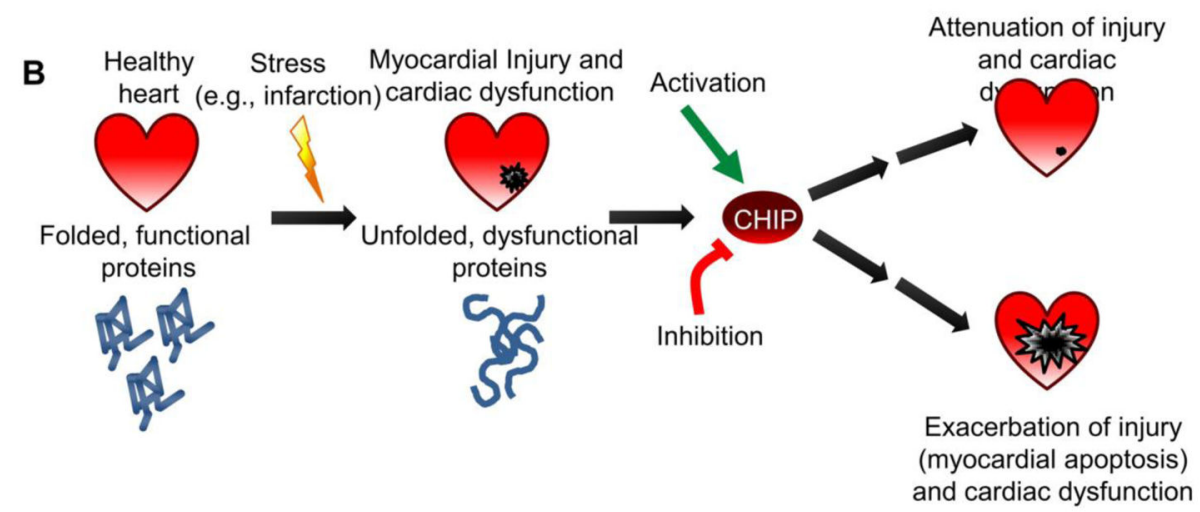

Figure 2. Role of CHIP-mediated ubiquitination of unfolded proteins in myocardial stress, e.g. infarction

A. Unfolded proteins accumulate within the cardiomyocyte when exposed to various biological stressors. CHIP promotes elimination of misfolded or unfolded proteins via ubiquitination in cooperation with co-chaperones heat shock cognate protein

70 (hsc70) and hsp70 in a BAG1-dependent manner, leading to the subsequent proteasomal degradation of dysfunctional proteins. B. However, myocardial stress can overwhelm CHIP's capacity to clear unfolded proteins, resulting in the formation of unfolded protein aggregates or toxic inclusion bodies that contribute to myocardial apoptosis. Activation of CHIP via increasing

CHIP expression attenuates myocardial injury following ischemia by preventing the accumulation of unfolded proteins and ensuing cell death. Conversely, inhibition of CHIP by CHIP deletion exacerbates cardiac injury following myocardial infarction.

Figure based on recently published reports [16, 55, 56, 100-107]. 


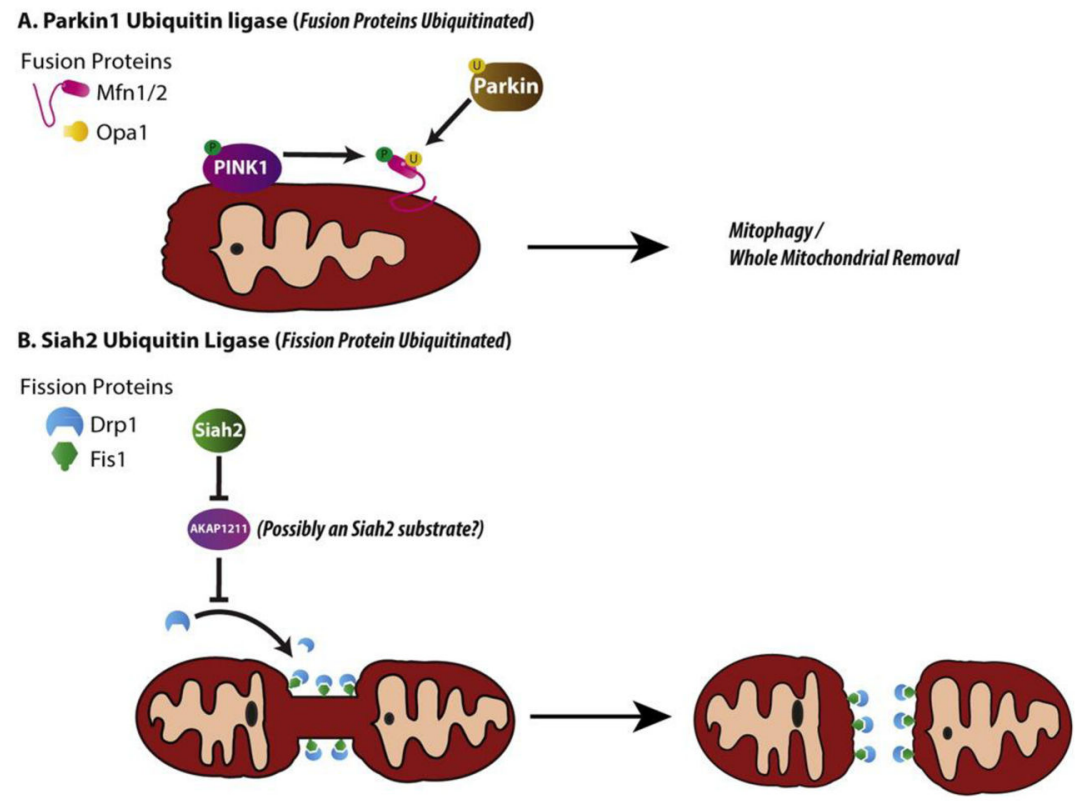

Figure 3. Post-translational ubiquitination regulates proteins involved in mitophagy and mitochondrial fission During mitochondrial fusion, Mfn1 facilitates the initial GTP-dependent outer mitochondrial membrane (OMM) tethering; Mfn2 then mixes the juxtaposed outer membranes and docks the inner mitochondrial membrane. Optic atrophy-1 (Opa1) then tethers the inner mitochondrial membranes at the cristae necks while maintaining the complex folded structure of the inner membrane.

During mitochondrial fission, the Fis1 protein localizes the dynamin-related protein-1 (Drp1) to the OMM and mediates constriction and scission, resulting in GTP-dependent mitochondrial division. Multiple ubiquitin ligases have recently been reported to regulate mitochondrial fission and fusion proteins. A. The cytosolic ubiquitin ligase parkin ubiquitinates Mfn2 when it is phosphorylated by the mitochondrial kinase PINK1, targeting damaged mitochondria for mitophagy. Loss of the inner mitochondrial membrane gradient stabilizes PINK1 on damaged organelles, which phosphorylate Mfn2. Parkin then ubiquitinates phosphorylated Mfn2, tagging Mfn2 for mitophagy [48]. B. The ubiquitin ligase Siah2 regulates the protein levels of the kinase AKAP121 during hypoxia-mediated mitochondrial fragmentation. Siah1a/2 inhibits AKAP121 activity, which normally functions to block the interaction between Drp1 and Fis1 [68]. 


\begin{tabular}{|c|c|c|c|c|c|c|c|c|c|c|}
\hline & 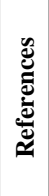 & 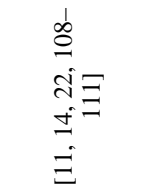 & $\begin{array}{l}\Xi \\
\Xi \\
\stackrel{\Xi}{\Xi}\end{array}$ & $\stackrel{\Xi}{\Xi}$ & 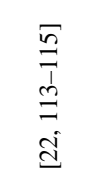 & 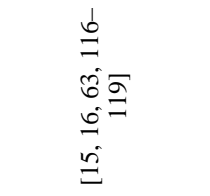 & $\begin{array}{l}\bar{\Xi} \\
\bar{\Xi} \\
\Xi \\
\Xi\end{array}$ & $\begin{array}{l}\bar{\Xi} \\
\dot{\vec{d}}\end{array}$ & $\overline{\mathbb{Z}}$ & $\begin{array}{l}\bar{\Xi} \\
\mathcal{U} \\
\mathbb{U}\end{array}$ \\
\hline & 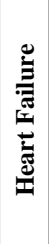 & 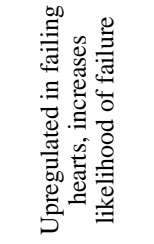 & త্ & $\stackrel{\circlearrowright}{\dot{I}}$ & $\stackrel{\check{I}}{\mathrm{I}}$ & 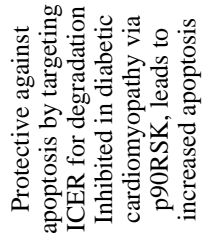 & $\stackrel{\check{I}}{\dot{I}}$ & ت্]ت & $\stackrel{\check{I}}{\mathrm{I}}$ & $\stackrel{\check{I}}{\ddot{I}}$ \\
\hline & 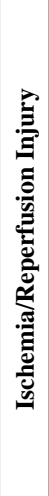 & 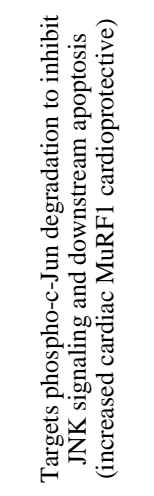 & $\stackrel{\ddot{J}}{\dot{I}}$ & 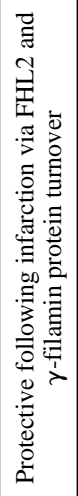 & 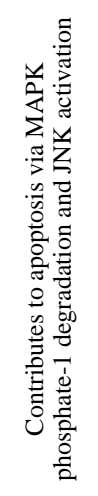 & 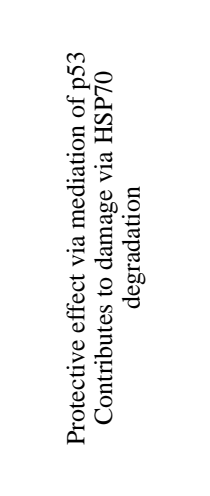 & 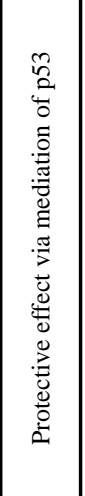 & 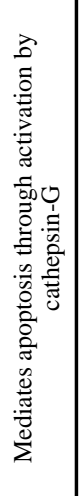 & 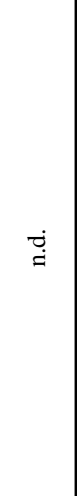 & 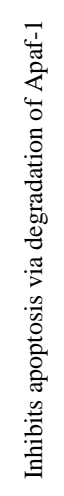 \\
\hline 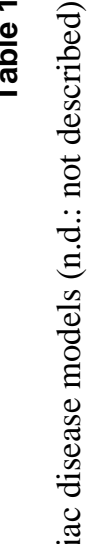 & 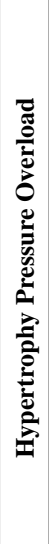 & 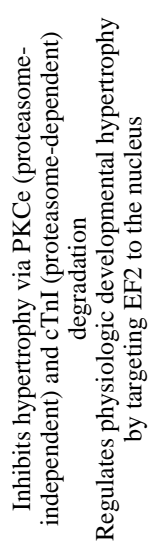 & 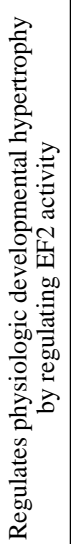 & $\stackrel{\check{I}}{\dot{I}}$ & 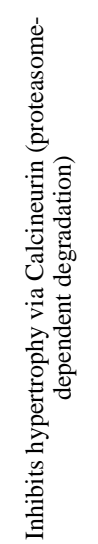 & 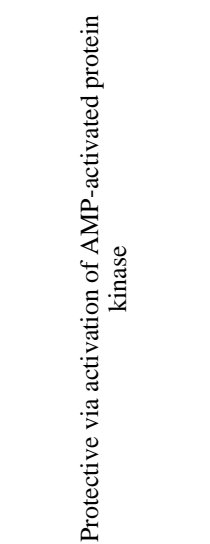 & 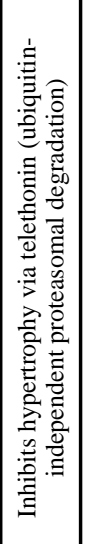 & 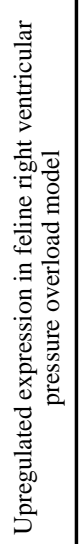 & 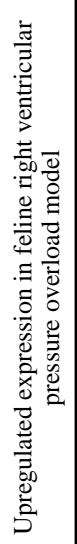 & 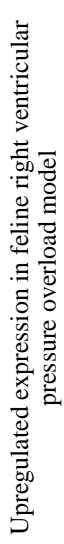 \\
\hline 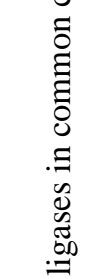 & 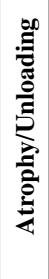 & 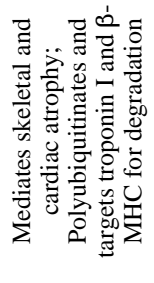 & త্ & త্ & 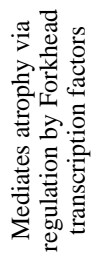 & ت্]ت & ت্ت & ت্] & త্ & $\stackrel{\check{I}}{\dot{I}}$ \\
\hline 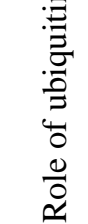 & & $\begin{array}{l}\overrightarrow{0} \\
\overrightarrow{2}\end{array}$ & 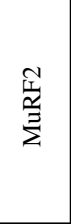 & 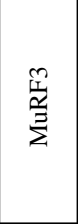 & 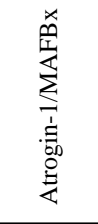 & 念 & $\stackrel{\Sigma}{\tilde{\Sigma}}$ & $\vec{j}$ & 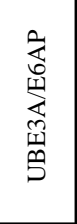 & $\frac{\mathrm{s}}{\mathrm{s}}$ \\
\hline
\end{tabular}




\section{Table 2}

Role of ubiquitin ligases in cardiac protein turnover

\begin{tabular}{|c|c|c|}
\hline Ubiquitin Ligase & Function & References \\
\hline $\begin{array}{c}\text { MuRF Family } \\
\text { MuRF1 } \\
\text { MuRF2 } \\
\text { MuRF3 }\end{array}$ & $\begin{array}{c}\text { Targets troponin I (MuRF1), } \beta \text {-MHC (MuRF1, MuRF3), MHCIIa (MuRF1, MuRF3) for } \\
\text { proteasome-mediated degradation } \\
\text { Interacts with titin (MuRF1, MuRF2, MuRF3), troponin T (MuRF1, MuRF2), MLC2 (MuRF1, } \\
\text { MuRF2), myotilin (MuRF1, MuRF2), telethonin (MuRF1, MuRF2), creatine kinase (MuRF1) }\end{array}$ & $\begin{array}{c}{[1,12,108,124-} \\
127]\end{array}$ \\
\hline CHIP & $\begin{array}{c}\text { Interacts with chaperones HSP 70, HSP90 and UNC-45 to mediate myosin degradation, folding } \\
\text { and sarcomere placement } \\
\text { Controls fine-tuning of AMPK activation in stress response by targeting LKB1 for degradation }\end{array}$ & {$[1,116,128]$} \\
\hline Fbx122 & Targets a-actinin-2 and filamin C for degradation & {$[7]$} \\
\hline c-Cbl & Activated by Cathepsin G to target focal adhesion and myofibrillar proteins for degradation, \\
including FAK, paxillin and troponin I & {$[31]$} \\
\hline Unknown & Regulates cMLCK levels to alter phosphorylation of MLC2v & {$[37]$} \\
\hline
\end{tabular}

